\title{
The Formal Research Group Model as an Undergraduate Retention Tool
}

\author{
Patricia A. Nava \\ Department of Electrical and Computer Engineering \\ The University of Texas at El Paso
}

\begin{abstract}
Undergraduate attrition is a problem in urban Texas State universities, where the graduation rate is lower than $40 \%$. A theory for college departure argues that this graduation rate could be increased significantly by increasing the frequency of formal social contacts (technical experiences outside of the classroom). These technical experiences can be in a research group, the benefits of which are that students develop domain expertise, gain an understanding and appreciation of the research process and its practice, and acquire team, communication, problemsolving, and higher-level thinking skills. Students with this experience are better prepared to address the remainder of their undergraduate curriculum successfully, as well as being equipped to attend graduate school. This paper describes a model developed to engage students in undergraduate research and to deliver the benefits and responsibilities of a small research lab to their hands. This model, based on the affinity group model, formalizes functional tasks within the lab as well as serving as a foundation for research mentorship. The implementation of the model, the Neuro-Fuzzy Systems Research Group, provides a mechanism and infrastructure that supports the development of students, both on a professional and personal level. The group uses structured activities to develop their research, technical, communication and group skills. The implementation of the model is discussed, as well as its specific characteristics, and its use as a retention tool.
\end{abstract}

\section{Introduction}

The attrition and low rate of success of undergraduate students, especially those belonging to under-represented minority populations, are becoming major issues in Higher Education. Current six-year graduation rates of Hispanic serving institutions in the Southwest United States range between 20 and $41 \%$. This low rate of successful completion is due to yearly attrition between 20 and $40 \%$ of the class. In order to increase this low rate of success, institutions must look for novel methods to encourage students to persist in their pursuit of a degree. One method that engages students academically and socially is the undergraduate research experience. Undergraduate research activities are known to promote goal setting and planning beyond graduation, thus affecting student retention. ${ }^{2}$

The affinity group model, being implemented at the University of Texas at El Paso's Department of Electrical and Computer Engineering, is more far-reaching than the usual research group. The Neuro-Fuzzy Systems Research Group seeks to engage students, develop them professionally and personally as well as accomplishing the research goals. As a by-product of the effective affinity group, the participants become ambassadors to the college and local community. In this 
manner, the research group becomes a recruitment device, too. This article discusses a model for retention and how the affinity group fulfills different facets of the model.

\section{Model for Institutional Departure/Retention}

The pursuit of a degree in engineering, science and mathematics is laden with pitfalls that can determine whether a student persists or departs without completing the degree. Tinto's formal model $^{3}$ for the student's decision to persist or depart incorporates two tracks (refer to Figure 1). Although many factors contribute to formulation of the initial intentions and goals, these goals are revisited, over time, and either reinforced or revised. In order for the goal of obtaining a degree to be reinforced, the student's level of integration into the college must create an institutional commitment that obligates the student to persist. (A high level of integration can serve as positive reinforcement to the original goals and the decision to persist. A low level of integration, which can be viewed conversely as a high level of alienation, might result in the decision to depart.)

The student's skills, abilities, prior school experience and family background all contribute to formulation of the student's original goals. With these goals in mind, the student proceeds to have a series of experiences in the academic system and the social system within the college. Each of these systems yields formal as well as informal interactions. The student's interactions within these systems will ultimately determine the student's level of integration and institutional commitment. This directly impacts the departure decision, for if the institutional commitment outweighs external commitment, the decision to continue is made.

PRE-ENTRY ATTRIBUTES GOALS/COMMITMENTS INSTITUTIONAL EXPERIENCES INTEGRATION GOALS/COMMITMENTS OUTCOME

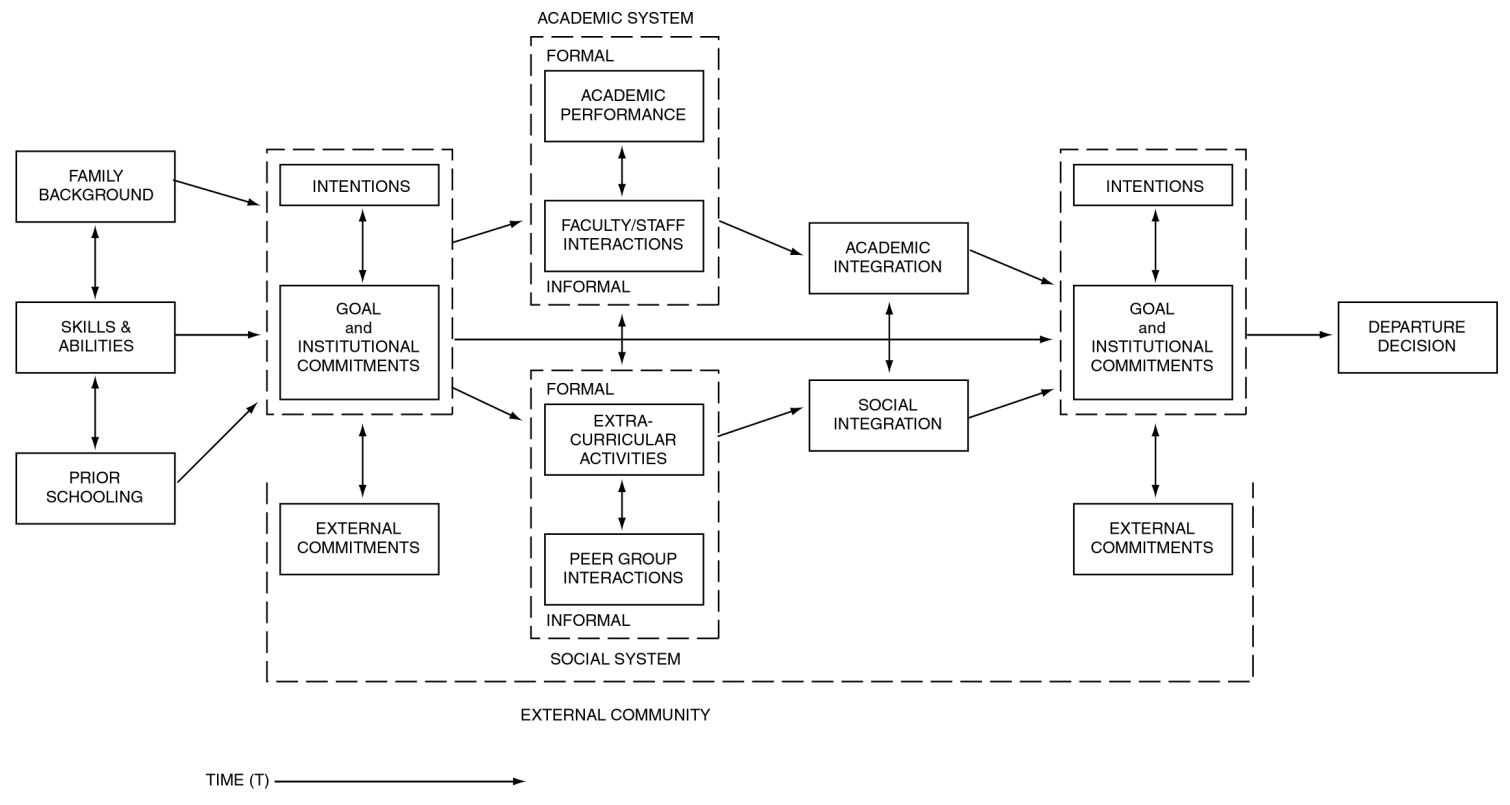

Figure 1. Theory for Institutional Departure [3]. 
The academic system consists of formal experiences such as lectures, classroom interactions and structured lab experiments. These activities yield an objective quantitative rating of the student's academic performance in the form of a grade and can serve to increase the level of academic integration. The informal experiences in the academic system are interactions between the student and faculty/staff, such as office hour visits, advising, scheduling, and tutoring. These activities yield an individual qualitative rating of academic integration.

The college social system interactions create a level of social integration, which can impact the departure decision as much as the academic system's factors. Formal social interactions consist of structured extracurricular activities such as research activities, professional society activities and college/departmental activities. The informal social system interactions occur in the peer group. These interactions occur in places where students congregate. Combined formal and informal experiences yield a level of social integration. If the student can assimilate the college culture, the level of social integration will be high, and the decision to persist will be reinforced. Conversely, if the student does not achieve integration, a sense of alienation will develop, yielding a scenario with a high probability of departure.

The amount and quality of interactions within the college create levels of integration, both social and academic. There are many different activities that can contribute to high level of integration that can be institutionalized. ${ }^{4}$ It is proposed that one facet of the formal social system, the research group, can have an impact beyond its role as defined in this model. Specifically, the research group when implemented with the affinity group model can have an impact on peer group interactions as well as improving academic performance, all of which contribute to a high level of integration and a decision to persist.

\section{The Affinity Group Model}

An Affinity Group ${ }^{5}$ is formed around a theme or technical topic, and seeks to not only facilitate the operation of a group, but also to train students in:

- technical skills (use of specialized software and special-purpose hardware),

- group skills (teaming, group task planning, and running effective meetings),

- professional skills (time management, leadership, task completion, effective presentations, and public speaking), and

- research skills and training (reading technical papers effectively, literature searches, planning and completing research tasks, learning case histories, and keeping abreast of current developments).

The Neuro-Fuzzy Systems Research Group (NFSRG) at the University of Texas at El Paso is an implementation of this model. The group's objective, beyond achieving research goals, is to develop the student as a professional and as a person. The method involves integrating the student to the extent that he or she assumes collective ownership for the laboratory and the group's accomplishments. The group's operation can be described in terms of four major categories: technical tasks, organizational tasks, professional development activities and group meetings. 
The technical tasks comprise the specific research goals of the group. At the beginning of the semester, a presentation is made on the overall research objectives and how each of the technical tasks dovetails to accomplish them. One important aspect of this category is the group composition. Each task is assigned to a team, which consists of three students. One graduate student and two undergraduates are the optimal combination. In this manner, a vertical integration of knowledge and research skills is obtained for each task. Additionally, this structure allows the team leader to develop leadership skills, as he or she is encouraged to delegate subtasks to other team members. The team members who are not team leaders are also encouraged to develop leadership skills in the form of organizational tasks.

The organizational tasks serve a dual purpose. Firstly, they develop a sense of ownership of the lab and subsequent responsibility for its success. Secondly, the tasks help develop managerial and professional skills. There are four organizational tasks: meeting management, laboratory management, resource management, and publicity.

Meeting management consists of organizing the weekly meetings. The group manager is responsible for collecting schedules and assigning meeting dates. Additionally, the manager must arrange for a speaker to present at each meeting, solicit discussion topics and assign a team member to take the minutes of the meeting. This student is also responsible for distributing meeting agendas and subsequent minutes, as well as conducting the meeting.

Laboratory management is responsible for the physical laboratory and its components. The team in lab management must maintain the equipment, and make suggestions for future equipment and software. They are also responsible for maintaining an adequate amount of computer and office supplies.

The resource management team is responsible for cataloging and maintaining all library, periodical and software acquisitions. These students have developed a system for checking out books and journals. Additionally, they maintain a database of technical conferences in order to advise the management team of upcoming deadlines for paper submission or conference registration.

The publicity team has developed a web page ${ }^{6}$ for the group, and updates it regularly. A list of current members, their technical task assignment and their curriculum vita gives them distinction among their peers. Additionally, the web page has an alumnus list that shows former members, their contributions, and a copy of their paper or thesis. They have also developed a brochure that is used for recruitment purposes. These brochures have been distributed at local high school outreach activities in order to attract talented local students. Each member of the NFSRG group is obligated to attend one outreach activity per year. This activity allows the group members an opportunity to exercise their communication skills by summarizing their experience to a nontechnical audience. In an effort to attract graduate students, the brochures have also been distributed in graduate school fairs at several national conferences.

Professional development activities include one formal presentation per semester to the NFSRG, a session on presentation software, and the requirement to participate in Research EXPOs. 
Additionally, the student is expected to collaborate on one article for a national conference. If possible, one of the student co-authors makes the presentation at the conference.

Meetings fall into two categories. The first, the NFSRG weekly meeting, provides a venue for the students to make announcements, have open discussion and talk about lab issues or problems. Additionally, students, one or two per week, make presentations and obtain feedback on their presentation style. The student can make a presentation on their work to date, thesis topic or review a technical article. The audience is given a form for evaluating the presenter. The forms allow the audience to rate the presenter on speech and body language as well as technical content of the speech. One part of the form asks the evaluator to make suggestions as to how the presenter can improve their presentation. This type of peer evaluation leads to discussion in a comfortable environment and subsequent improvement in style. NFSRG members are required to submit a monthly report detailing their progress, plans and action items for the next month. The second meeting, in addition to NFSRG weekly meetings, is specialized to the technical task team. Each team meets with the faculty mentor to gauge progress of the research tasks and maintain appropriate direction of the effort.

\section{Impact}

Although the group is rather small, the students congregate in the lab, help each other with homework and have become a working entity. Because of interaction outside the boundaries of the research goal, the NFSRG has more impact than just that of formal social interaction in Tinto's model for institutional departure. Their cooperation in classwork outside of the classroom impacts their academic performance, which contributes to integration in the formal academic system. These peer group interactions continue within the classroom, and reinforce the informal social system of the college. ${ }^{7}$ Their interaction with the NFSRG faculty mentor has loaned them some familiarity and comfort in dealing with other faculty, thus reinforcing the informal academic system. Their cooperation has led to friendship and therefore increased their level of integration in the informal college social system. Viewed in this manner, the affinity group has more impact than the conventional research experience cited as the formal social system. The effect of these systems on retention can be illustrated by examining the results of the NFSRG.

The result of NFSRG implementation of the affinity model can be summarized by the information shown in Table 1. Specifically, all participants who have left the group have reached their original goal of completing a degree and obtaining a position in industry. Of those who have graduated, three have chosen to pursue a graduate degree within the group and four are working in industry.

Although this work represents a small number of participants, it corresponds to a perfect record for retention and success. The true impact will come from permeation of the model, to where all research groups open their structure to accept undergraduates. By allowing undergraduates to participate in research, the formal social interaction category is fulfilled. By implementing the research group as an affinity group, however, it serves to reinforce all four types of institutional experiences. This, in turn, increases institutional commitment and leads to reinforcing the students' goal of completing the degree. 
Table 1: Summary of NFSRG Participants and Their Activities

\begin{tabular}{|l|c|l|l|l|}
\multicolumn{1}{|c|}{ Participant } & Sex & \multicolumn{1}{c|}{ Degree Status } & \multicolumn{1}{c|}{$\begin{array}{c}\text { Poster/Art./Conf. } \\
\text { Presentation }\end{array}$} \\
\hline Calles, E.* & M & Completed BSEE - initiating grad studies & Poster \\
\hline Cano, J.* & F & $\begin{array}{l}\text { Completed BSEE - continuing with grad } \\
\text { studies }\end{array}$ & Poster \\
\hline Contreras, G.* & M & Continuing BSEE studies & $\begin{array}{l}\text { Poster, Article and } \\
\text { Conference Present. }\end{array}$ \\
\hline DeLaFuente, R.* & M & Completed BSEE - initiating grad studies & Poster \\
\hline Granda, V.* & F & Graduate Student & N/A (new participant) \\
\hline Kawaguchi, K. & M & Completed MSEE - employed & Poster, Article \\
\hline Ledezma, H.* & F & Completed BSEE - employed & Poster \\
\hline Lucero, Y.* & F & Completed BSEE and MSEE - employed & $\begin{array}{l}\text { Poster, Article and } \\
\text { Conference Present. }\end{array}$ \\
\hline Martinez, F.* & M & Graduate Student & N/A (new participant) \\
\hline Saenz, J.* & M & Continuing BSEE studies & Poster \\
\hline Sierra, R.* & M & Completed BSEE - employed & Poster \\
\hline
\end{tabular}

$*$ - under-represented minority

\section{Acknowledgments}

This work was funded by a NASA Faculty Award for Research. Additional funding was obtained through the UTEP Undergraduate Research Experience Program funded by the NSF Model Institutions for Excellence Program.

Bibliography

1. The Chronicle of Higher Education, Almanac Issue, Vol. XLVII, No. 1, September 1, 2000.

2. S.R. Gregerman et al., "Undergraduate Student-faculty research Partnerships Affect Student Retention," The Review of Higher Education, vol. 22, no. 1, pp. 55-71, 1998.

3. Vincent Tinto, Leaving College, Second Edition, the University of Chicago Press, 1993.

4. B.C.Flores et al., "Undergraduate Student Retention Strategies for Urban Engineering Colleges," Proceedings of the ASEE Gulf-Southwest Conference, 2000.

5. Ann Gates et al., "Expanding Participation in Undergraduate Research Using the Affinity Research Model," Journal of Engineering Education, vol. 88, no. 4, pp. 409-414.

6. URL: http://www.ece.utep.edu/research/webfuzzy/

7. Thomas Brady et al., "Building Learning Communities: The Experience of a Major State University with a Predominantly Hispanic Student Body," Proceedings of the $10^{\text {th }}$ Annual Project Kaleidoscope Meeting, University of Maryland College Park, p. 23, 1999.

\section{PATRICIA A. NAVA}

Patricia A. Nava is an Assistant Professor of Electrical and Computer Engineering at the University of Texas at El Paso. She serves as counselor to the IEEE Student Chapter and as co-advisor to TВП. Dr. Nava received a Ph.D. in Electrical Engineering from New Mexico State University in 1995 and is a registered Professional Electrical Engineer in Texas. 